\title{
ECC
}

\section{Preparation and identification of nanoparticle of lanthanum oxide and its application as antibacterial agent}

\author{
Elnaz Naderi, Niloufar Akbarzadeh-T*, Tahere Kondori, Abouzar Tahkor \\ Department of Chemistry, University of Sistan and Baluchestan, P.O. BOX 98135-674, Zahedan, Iran
}

Received: 13 April 2019, Accepted: 30 June 2019, Published: 1 November 2019

\begin{abstract}
In this research, nanoparticle of lanthanum oxide (a) has been synthesized in a coprecipitation method and its ability to be antibacterial has been studied. The $\mathrm{La}_{2} \mathrm{O}_{3}$ crystalline nanoparticle (a) was prepared at a nominal temperature of $673 \mathrm{~K}$ for 4 hours. The samples were identified using FT-IR, XRD, VSM, SEM, and EDX methods. Using the infrared spectroscope (FT-IR), the covalent bonding of $\mathrm{La}_{2} \mathrm{O}_{3}$ in the sample is confirmed. X-ray diffraction (XRD) shows that the single-phase sample has a hexagonal structure with average particle size $69 \mathrm{~nm}$. Moreover, the size of the particles seen in the SEM images corresponds to each other. Using the Vibration Sample Magnetometer (VSM), the magnetic properties of the nanoparticle (a) were studied and the result shows that the nanoparticle has paramagnetic behavior. The antibacterial effects were also examined in vitro against standard bacterial strains, the Gram-positive Staphylococcus aureus; S. aureus ATCC 25923 and Enterococcus faecalis; Enter faeca ATCC 29212, and also the Gram-negative Escherichia coli; E. coli ATCC 25922 and Pseudomonas aeruginosa; P. aeruginosa ATCC 27853. Using these strains, the minimum inhibitory concentration (MIC), minimum bactericidal concentration (MBC) and inhibition zones (IZ) were obtained. Antibacterial activities of lanthanum oxide nanoparticle are more than agents lanthanum salts.
\end{abstract}

Keywords: Nanoparticle; bacteria; escherichia coli.

Introduction

Preparation of various nano-materials have many different synthetic approaches such as chemical vapor deposition (CVD), hydrothermal, chemical bath deposition, laser ablation, thermal evaporation, sol-gel, homogeneous precipitation in an organic matrix, and sonochemical method [1-9]. Recently, nanoparticles have been discussed in two sections, metallic and non-metallic [10]. Metallic nanoparticles are used in insecticides and bactericides for many years [11]. The making and preparation of inorganic materials that have specific morphology and size, attracted considerable attention [12-15] and promising materials. It displys that nano-scale of materials show different properties relative to the same material in bulk form [16-18]. Bacteria are a group of microscopic organisms that surround a fairly thick outer covering. They have simple structures and belong to prokaryotic cells. Metal oxide 
nanoparticles exhibit different antibacterial properties based on surface to volume ratio. Gram-positive bacteria exhibit more resistance than gram-negative bacteria against metal nanoparticles, which can be related to the structure of the cell wall. Staphylococcus aureus is one of the most important pathogenic bacteria in hospital infections. Staphylococcus aureus is a major pathogen for humans and is responsible for food poisoning and non-intestinal infections such as skin infection, ulcers, and abdominal abscesses. Escherichia coli has a fecal origin due to its digestive tract and can be easily spread through humans and animals. In this work, the $\mathrm{La}_{2} \mathrm{O}_{3}$ crystalline nanoparticle was prepared, characterized, and tested for potential antibacterial activity against diverse microorganisms, namely the Gramnegative standard strain (Escherichia coli; E. coli ATCC 25922and Pseudomonas aeruginosa ATCC 27853) and the Gram- positive standard strain (Staphylococcus aureus; S. aureus ATCC 25923 and Enterococcus faecalis).

\section{Experimental}

Material and methods

All the used chemicals are of sufficient purity and are used without further purification. All chemicals and solvents are from Merck Chemical Company. In this research, we used an infrared spectroscopy (FT-IR), X-ray diffraction (XRD), scanning electron microscopy (SEM), energy diffraction spectroscopy (EDX) to identify synthesized nanoparticle. Infrared spectrum (400$4000 \mathrm{~cm}^{-1}-\mathrm{CsBr}$ ) of solid samples was taken as $1 \%$ dispersions by a Shimadzu-470 spectrometer. The magnetic properties of synthesized nanoparticle have been studied using a VSM (American VSM) Spectrometry (VSM) in the University of Sistan and Baluchestan. XRD measurements were carry out on X'pertdiffractometer by using graphite monochromatic $\mathrm{Cu}$ $\mathrm{K}_{\alpha}$ radiation in the $2 \theta$ range of $26-55^{\circ}$.

Preparation of $\mathrm{La}_{2} \mathrm{O}_{3}$ nanoparticle (a) in sedimentary method

In order to synthesize lanthanum nanoparticle (a) in sediment, to a $50 \mathrm{ml}$ solution of $\mathrm{La}\left(\mathrm{NO}_{3}\right)_{3} \cdot 6 \mathrm{H}_{2} \mathrm{O}(0.1 \mathrm{M})$ as a precursor was added small amount of oleic acid as surfactant. The solution was placed on a stirrer. In the next step, a solution of $0.2 \mathrm{M} \mathrm{NaOH}$ was added to this mixture dropwise. After the completion of this step, the obtained sediment was thoroughly washed with water. The resulting precipitate was dried and put in a furnace at $673 \mathrm{~K}$ for 4 hours until the rest of the organic material get out of it and lanthanum oxide was prepared $(\mathrm{R}=\% 63)$.

\section{Result and discussion}

FT-IR spectra of precursor compound and nano-particles (a) show in Figure (1a) and Figure (1b) respectively. Figure (1a) shows FT-IR spectra of Crude compound(a). The broad band observed at $2500-2925 \mathrm{~cm}^{-1}$, attributed to overlap of stretching vibration frequency of the acidic $\mathrm{OH}$ screw with $\mathrm{CH}$ bands. The bonds observed at 3006 $\mathrm{cm}^{-1}, 1712 \mathrm{~cm}^{-1}, 1378 \mathrm{~cm}^{-1}$ and $1465 \mathrm{~cm}^{-}$ 1 assign to $\mathrm{CH}, \mathrm{C}=\mathrm{O}, \mathrm{CH}_{2}$ and $\mathrm{CH}_{3}$ groups, respectively. [19-23]

As it can be observed in (Figure 1b) that all the bands of the oleic acid have been disappeared when the precursor product was thermalized in $673 \mathrm{~K}$ ) and only band was appeared at $500 \mathrm{~cm}^{-1}$. This band attributed to La-O indicating the formation of $\mathrm{La}_{2} \mathrm{O}_{3}$. [24]. 


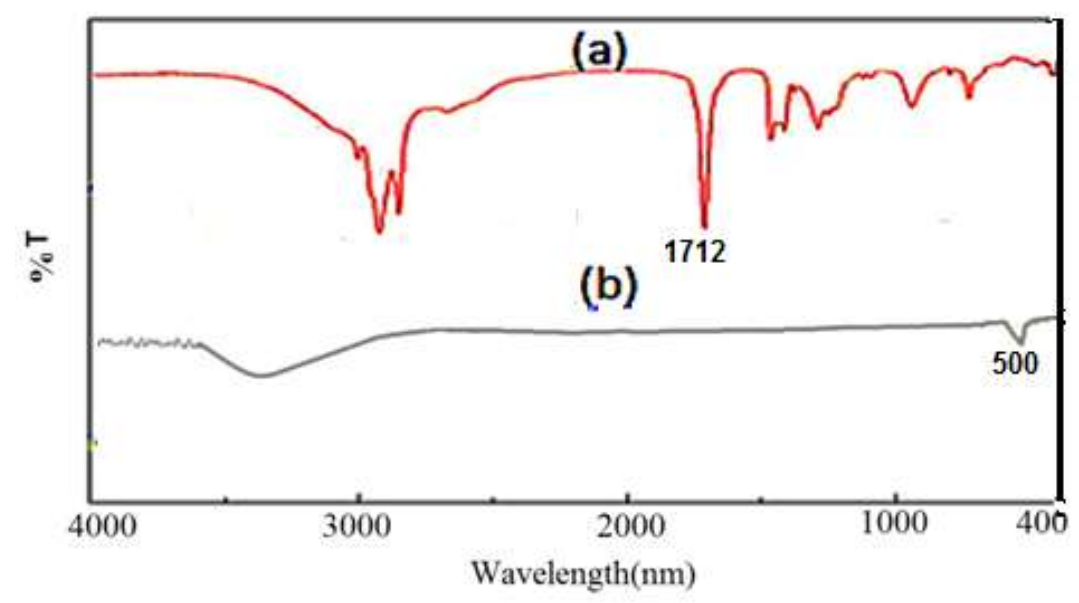

Figure 1. FT-IR spectra, a) precursor compound, b) nanoparticle in the $400-4000 \mathrm{~cm}^{-1}-\mathrm{CsBr}$

The XRD pattern of $\mathrm{La}_{2} \mathrm{O}_{3}$ nanoparticle is shown in Figure 2. Specifically, the position and relative intensities of all peaks confirmed well with standard XRD pattern of (JCPDS card No. 01-073-2141). The diffraction peaks can be indexed to pure nanoparticle (a) with orthorhombic phase.

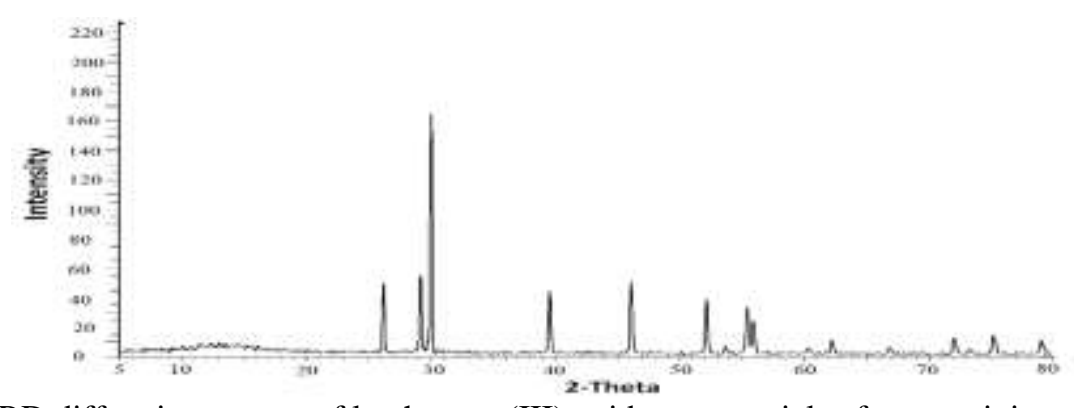

Figure 2. XRD diffraction pattern of lanthanum (III) oxide nanoparticle after premixing at $673 \mathrm{~K}$

The crystallite size of the title nanoparticle (a) was calculated using the Debye-Scherre formula from the major diffraction peak of the corresponding particle. The average diameter size the $\mathrm{La}_{2} \mathrm{O}_{3}$ calculated 69 nm. Maximum diffraction is in $2 \theta=29.44$ and $(011)$ as miller indices. The distance between crystalline planes is $\mathrm{d}=2.97 \AA$ [25-27].

The surface morphology, structure and size of the nanoparticle (a) were carried out using SEM image. The SEM image of title nano particle (a) is clear. So provided in the form of nanoparticle (a) and almost the morphology and uniformity in the image of them, relatively porous and beneath the high porosity for use as a catalyst for much is suitable. Figure 3 show the SEM image of the prepared $\mathrm{La}_{2} \mathrm{O}_{3}$ nanoparticle. 


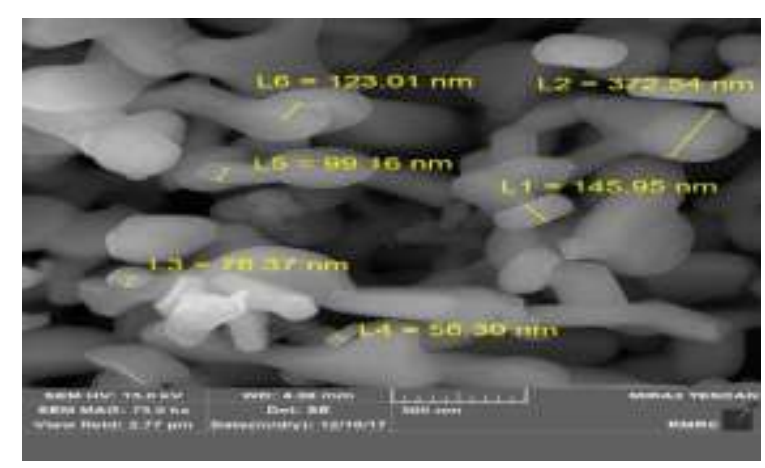

Figure 3. SEM images of nanoparticle (a)

The EDX spectrum of nanoparticle synthesized sample consists of oxygen, (a) of lanthanum oxide is shown in lanthanum. The weight percent and the Figure 4. Based on these results, the mass of the elements listed in Table 1.

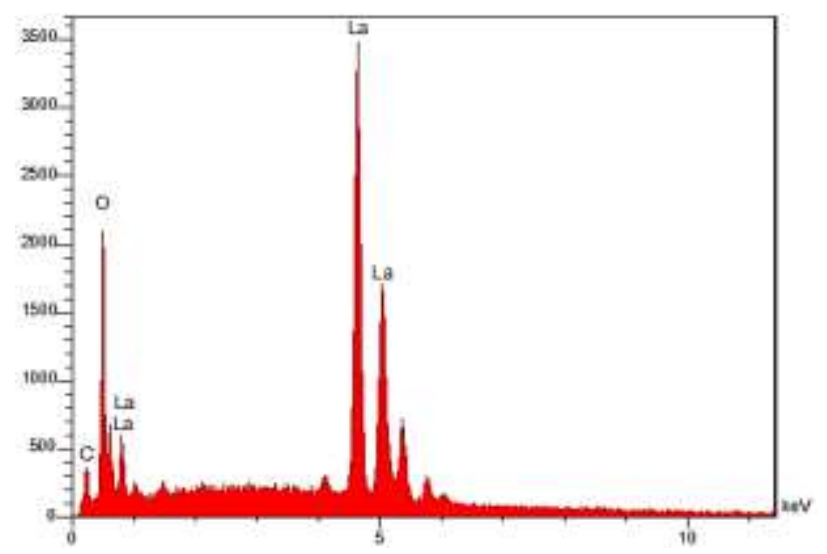

Figure 4. EDX spectrum of nanoparticle (a)

Table 1. EDX data of lanthanum oxide nanoparticle

\begin{tabular}{ccc}
\hline Element & W\% & A\% \\
\hline C & 1.14 & 9.49 \\
O & 8.68 & 54.26 \\
La & 50.29 & 36.21 \\
\hline
\end{tabular}

The magnetic properties of lanthanum oxide nanoparticle (a) in a magnetic field of 10,000 to $-10,000$ overstep are shown in Figure 5. This curve lacks a hysteresis loop which indicates that nanoparticle (a) has paramagnetic behavior. 


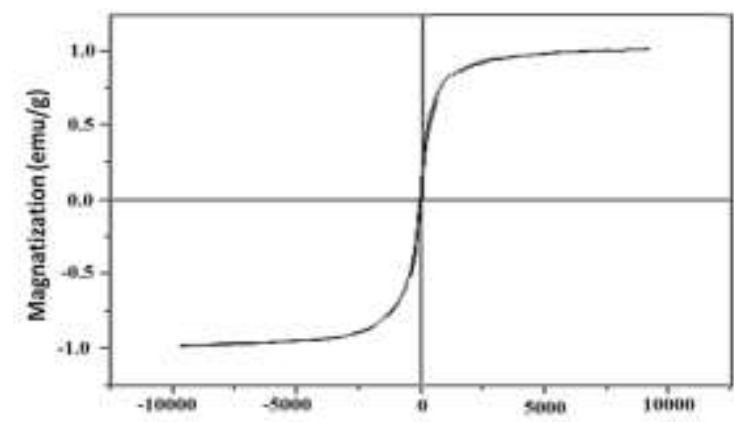

Figure 5. VSM graph of nanoparticle (a)

Antibacterial properties of lanthanum oxide nanoparticle (a)

The minimum inhibitory concentration (MIC), minimum bactericidal concentration (MBC) and inhibition zones (IZ) of lanthanum oxide nanoparticle (a), were screened against two gram-positive standard strains (Staphylococcus aureus; S. aureus ATCC 25923) and two gram-negative standard strains (Escherichia coli; E. coli ATCC 25922). In these experiments, cefazolin was used as a standard confirmed antibacterial. The results are summarized in Table 2. Data on Table 2 show that lanthanum oxide nanoparticle exhibit antibacterial activity. Moreover, the lanthanum oxide nanoparticle are more potent antibacterial agents against the grampositive than those of the gram-negative bacteria, comparison of the antimicrobial activities of the lanthanum salts.

Table 2. Results of microbial properties

\begin{tabular}{lccc}
\hline \multicolumn{1}{c}{ Bacteria } & MIC $(\boldsymbol{\mu g} / \mathbf{m L})$ & MBC $(\boldsymbol{\mu g} / \mathbf{~ m L})$ & IZ \\
\hline Staphylococcus aureus & 0.0062 & 0.0125 & 24 \\
Enterococcus faecalis & 0.0125 & 0.025 & 23 \\
Escherichia coli & 0.0250 & 0.0250 & 19 \\
Pseudomonas aeruginosa & 0.0125 & 0.0125 & 18 \\
Cefazolin $^{*}$ & - & - & 29 \\
\hline
\end{tabular}

*(as negative control) against investigated bacterial strains

\section{Conclusion}

In summary, we synthesized nanoparticles of lanthanum oxide by a co-deposition method at $673 \mathrm{~K}$ for 4 hours. The nanoparticles (a) were recognized using the techniques such as SEM, XRD, VSM and EDX. The size of lanthanum oxide nanoparticles (a) was obtained by SEM and XRD methods. The image of nanoparticles (a) showed that uniform and porous morphology and particle size are almost identical. Based on the major band, the average size of $\mathrm{La}_{2} \mathrm{O}_{3}$ was found to be around $69 \mathrm{~nm}$. The magnetic properties of the nanoparticle were investigated by the VSM, which show super paramagnetism. The MIC, MBC and IZ 
of the nanoparticles (a), were screened against two gram-positive standard strain (Staphylococcus aureus; S. aureus ATCC 25923 and Enterococcus faecalis; Enter_faeca ATCC 29212) and also two gram-negative standard strain (Escherichia coli; E. coli ATCC 25922 and Pseudomonas aeruginosa; $P$. aeruginosa ATCC 27853). The lanthanum oxide nanoparticle are potent antibacterial agent, against grampositive than that of gram-negative bacteria under investigation.

\section{Acknowledgements}

The authors sincerely thank the University of Sistan and Baluchestan for providing financial support of this work.

\section{References}

[1] Y. Wu, P. Yang, Chem. Mater., 2000, 12, 605-607.

[2] M. Khorasani-Motlagh, M. Noroozifar, A. Ahanin-Jan, J.Chem. Soc., 2012, 9, 833-839.

[3] Y. Wu, P. Yang, Chem. Mater., 2000, 12, 605-607.

[4] Y.G. Zhang, H.Y. He, B.C. Pan, J. Phys. Chem. C, 2012, 116, 2313023135.

[5] A.M. Morales, C.M. Lieber, Science., 1998, 279, 208-211.

[6] C. Suciu, L. Gagea, A.C. Hoffmann, M. Mocean, Chem. Eng. Sci., 2006, 61, 7831-7835.

[7] M. Salavati-Niasari, G. Hosseinzadeh, F. Davar, J. Alloys Compd., 2011, 509,134-140.

[8] M. Ranjbar, O. Çelik, S.H. Mahmoudi Najafi, Sheshmani, N. Akbari Mobarakeh, J. Inorg.Organomet.Polym., 2012, 22, 837-844.

[9] P. Calvo, C. Remunan-Lopez, J.L. Villa-Jato, M.J. Alonso, J.Appl. Polym. Sci., 1997, 63, 125-132.
[10] Y.G. Sun, B. Mayerrs, T. Herricks, Y.N. Xia, J. Nano Lett., 2003, 3, 955960.

[11] W. Te-Hsing, T. Yi-Der, S.T. LieHang, J Solid State Phenomena., 2007, 124,1241-1244.

[12] V.P. Singh, R.S. Singh, G.W. Thompson, V. Jayaraman, S. Sanagapalli, V.K. Rangari, Sol. Energy Mater.Sol.Cells., 2004, 81, 293-303.

[13] G.H. Shahverdizadeh, A. Morsali, J. Inorg.Organomet. Polym. Mate., 2011, 21, 694-699.

[14] M. Payehghadr, V. Safarifard, M. Ramazani, A. Morsali, J. Inorg.Organomet. Polym., 2012, 22, 543-548.

[15] L. Hashemi, M. Hosseinifard, V. Amani, A. Morsali, $J$. Inorg.Organomet. Polym. Mater., 2013 , 23, 519-524.

[16] G. Marban, A. Lopez, I. Lopez, T. Valdes-Solis, Appl. Catal., B., 2010 , 99, 257-264.

[17] T. Valdes-Solis, G. Marban, A.B. Fuertes, Catal. Today, 2006, 116, 354360.

[1[18] S.D. Jones, L.M. Neal, M.L. Everett, G.B. Hoflund, E.H.H. Weaver, Appl. Sur. Sci., 2010, 256, 7345-7353.

[19] K. Nakamato, Wiley-Interscience, New York, 2009.

[20] G. Zhao, H. Lin, Y. Ping, H. Sun, S. Zhu, S. Xuncheng, Y. Chen, J. Inorg. Biochem., 1999, 73, 145-149.

[21] V. Amani, N. Safari, H.R. Khavasi, M. Akkurt, Polyhedron., 2009, 28, 3026-3030.

[22] G. A.Pitsevich, A.E. Malevich, E.N. Kozlovskaya, I.Y. Doroshenko, V. Sablinskas, V.E. Pogorelov, V. Balevicius, Vib. Spectrosc., 2015, 7, 67-75.

[23] L. Zhang, R. He, H.C. Gu, Appl. Surf. Sci., 2006, 253, 2611-2617. 
[24] H. Saravani, M. Khajehali, Orient. J. Chem., 2016, 32, 491-498.

[25] X. Ge, Y. Liu, X. Liu; Sensors and Actuators B: Chemical., 2001, 79, 171174.
[26] H.P. Klug, L.E. Alexander, 1974, 992. ISBN 0-471-49369-4. Wiley$\mathrm{VCH}$.

[27] K. Parimalagandhi, S. Vairam, Orient. J. Chem., 2014, 30, 1957-1963.

How to cite this manuscript: Elnaz Naderi, Niloufar Akbarzadeh T, Tahere Kondori, Abouzar Tahkor. "Preparation and identification of nanoparticle of lanthanum oxide and its application as antibacterial agent". Eurasian Chemical Communications, 2020, 2(2), 265-271. 